\title{
Adherence in Asthma and COPD: New Strategies for an Old Problem
}

\author{
Maureen George PhD RN AE-C
}

\author{
Introduction \\ Adherence \\ Medication Adherence in Asthma and COPD \\ Asthma and COPD Patients Are Non-Adherent to More Than Just Their \\ Medications \\ Types of Non-Adherence \\ Dimensions of Non-Adherence \\ Socioeconomic Factors \\ Therapy-Related Factors \\ Condition-Related Factors \\ Health System-Related Factors \\ Patient-Related Factors \\ Ways to Measure Adherence \\ Biochemical Measurement \\ Provider Estimate \\ Patient Self-Report \\ Prescription Data \\ Electronic Monitors and Smart Technology \\ Strategies to Improve Adherence \\ Strategies to Reduce Unintentional Non-Adherence \\ Innovative Strategies to Reduce Intentional Non-Adherence \\ Summary
}

\begin{abstract}
Adherence broadly encompasses the decisions patients make as to whether health care advice should be initiated, as well as the degree to which the recommended health behaviors, once started, are maintained. Disease-related conditions such as severity and duration of illness, as well as treatment-related features such as frequency of dosing and side effects, are $\mathbf{2}$ of several factors that influence adherence. Other factors affecting adherence include socioeconomic status, patient-related causes, and health system-related reasons. Adherence is rarely, if ever, an all-or-none phenomenon. Typically, patients follow some recommendations closely while deciding others are optional; these decisions are often made without consulting with or notifying health care professionals. Non-adherence can be categorized as either unintentional or intentional. Unintentional non-adherence is easier to remedy because it responds to patient education, simplification of treatment regimens, or the use of a reminder system. Intentional non-adherence is more complex and challenging to address because patients exhibiting these behaviors often do not find evidence-based recommendations compelling, lack the motivation to follow advice, or have deeply entrenched personal beliefs that conflict with health guidance. Novel psychotherapeutic behavioral interventions, such as shared decision-making, motivational interviewing, and coaching are some approaches being tested to determine their effectiveness in mitigating the resistance to treatment that characterizes intentional non-adherence in asthma and COPD populations. In this narrative review, the extent of non-adherence to asthma and COPD management recommendations is explored, the
\end{abstract}




\begin{abstract}
factors affecting adherence are explicated, the methods used to measure adherence are compared and contrasted, and the effectiveness of strategies targeting unintentional and intentional nonadherence is detailed. Key words: adherence; asthma; COPD; shared decision-making; motivational interviewing; behavioral interventions; coaching; navigator; smart inhalers [Respir Care 2018;63(6):818-831. (c) 2018 Daedalus Enterprises]
\end{abstract}

Keep a watch also on the faults of the patients, which often make them lie about the taking of things prescribed. ${ }^{1}$ -Hippocrates

\section{Introduction}

Chronic illness is the leading cause of disability and death worldwide, and nearly half of all adults in the United States suffer from one or more chronic illnesses, ${ }^{2}$ including chronic respiratory illnesses. More than 25 million American children and adults have asthma, ${ }^{3}$ and more than 12 million adults are affected by COPD. ${ }^{4}$ By 2030 , COPD is expected to be the third leading cause of mortality globally. ${ }^{5}$ Risk of death from asthma and COPD are significantly increased when pharmacologic management is not initiated or is not sustained. ${ }^{6}$

\section{Adherence}

The negative physical and psychological consequences of chronic disease can largely be reduced with optimal self-management. However, chronic disease management takes place at home, with patients and their loved ones making decisions as to whether treatments should be started or continued, often without consulting the health care team. ${ }^{7}$ As such, patients may focus on their own experiences of health, finding externally specified disease management strategies, such as evidence-based guideline-directed care, inadequately compelling. The process and outcome of these decisions are described as adherence: the extent to which a person's behavior (eg, taking medication, following a diet, or executing lifestyle changes) corresponds with

Dr George is affiliated with the Columbia University School of Nursing in New York, New York.

Dr George presented a version of this paper at the 56th RESPIRATORY CARE Journal Conference, Respiratory Medications for COPD and Adult Asthma: Pharmacologic Actions to Clinical Applications, held June 2223, 2017, in St Petersburg, Florida.

Dr George has disclosed relationships with Teva and Astra Zeneca.

Correspondence: Maureen George PhD RN AE-C, Columbia University School of Nursing, 630 West 168th Street, Mail Code 6, New York, NY 10032. E-mail:mg3656@cumc.columbia.edu.

DOI: $10.4187 /$ respcare. 05905 agreed-upon recommendations from a health care provider. ${ }^{8}$ Adherence and related expressions, such as concordance and therapeutic alliance, are preferred over terms like compliance because adherence suggests patient autonomy, whereas compliance connotes a paternalistic model of care in which patients are expected to dutifully acquiesce to health care advice. With adherence comes the idea of intentional persistence that better reflects the complexity of chronic disease management. ${ }^{9}$

There are no known factors that reliably predict adherence. ${ }^{8,10-12}$ Furthermore, adherence is not an all-or-none phenomenon but rather a set of dynamic behaviors that change over time and context. Because self-management decisions are largely based on patients' experiences and beliefs about health and illness, every conceivable pattern of adherence can be seen. For example, patients' medication-taking behaviors may range from close alignment with evidence-based recommendations to chronic underuse of all medications and even outright rejection of Western biomedical approaches. ${ }^{13}$ While these extremes are less common, a more complicated picture frequently emerges in which medications are sometimes but not always used. For example, adherence rates are highest immediately before and after office visits and lowest between visits. ${ }^{14-16}$

\section{Medication Adherence in Asthma and COPD}

In asthma and COPD, maintenance treatments are underused. In a systematic review of 29 randomized controlled trials of $>2,000$ subjects with asthma using inhaled corticosteroids (ICS), adherence ranged from $47-57 \%,{ }^{17}$ while in a study of 244 subjects with COPD, objective measurements of adherence to a combination product (ICS and long-acting bronchodilator) was $<23 \% .{ }^{18}$ Non-persistence (ie, stopping after starting) with long-acting bronchodilators was found to occur at a rate of $65 \%$ in an analysis of $>45,000$ subjects with COPD in Germany ${ }^{19}$ and in $70 \%$ of $>11,000$ patients with COPD in the U.S. Veterans Affairs database. ${ }^{20}$ In fact, adherence in pulmonary disease is lower than that for other chronic conditions, including HIV, rheumatologic conditions, cancer, and gastrointestinal disorders..$^{21}$ At the same time, there is an overreliance on short-acting bronchodilators, a marker of disease activity, in both asthma and COPD. ${ }^{22,23}$

These data reflect medication adherence rates for patients who have made the decision to initiate a trial of 
Table 1. Examples of Intentional and Unintentional Non-Adherence

\begin{tabular}{|c|c|}
\hline Causes of Unintentional Non-Adherence & Causes of Intentional Non-Adherence \\
\hline Forgetfulness & Does not find health care advice or evidence-based recommendations compelling \\
\hline Disrupted routines & Has cultural or alternative beliefs about the meaning of symptoms or illness \\
\hline Lack of routines & that conflicts with the biomedical model \\
\hline Treatment regimen is too complicated & Holds discordant beliefs regarding diagnosis, severity, and treatment required \\
\hline Lacks understanding of disease or duration of required treatment & Lacks motivation to persist with treatment \\
\hline Lacks understanding of treatment use (eg, thinks inhaled & Distrusts health care professionals and/or health care systems \\
\hline corticosteroids are to be used only when symptomatic) & Feels disenfranchised from the decision-making process \\
\hline Inaccurate administration technique for inhaled therapies & $\begin{array}{l}\text { Fears that tolerance or addiction to inhaled corticosteroids can occur if used } \\
\text { routinely, confuses anabolic steroids with corticosteroids, or misattributes } \\
\text { systemic adverse effects to topical treatment }\end{array}$ \\
\hline
\end{tabular}

prescribed medicine, that is, they have obtained their initial prescription from the pharmacy. However, a not inconsequential number of individuals never fill or pick up their first prescription, a behavior described as primary non-adherence. In one retrospective cohort study of $>69,000$ members of 5 large health plans, $14-20 \%$ of subjects with asthma were identified as having primary non-adherence. ${ }^{24}$

\section{Asthma and COPD Patients Are Non-Adherent to More Than Just Their Medications}

As implied by the definition of adherence, management of chronic respiratory diseases requires more than just taking the medicine. Individuals with chronic respiratory diseases may also be expected to stop smoking, attend routine ambulatory appointments (eg, cardiopulmonary rehabilitation programs), implement environmental remediation and avoidance measures, monitor air flow at home using peak flow meters or hand-held spirometers, respond to increasing symptoms using tailored action plans, gain or lose weight, and adhere to long-term oxygen therapy. Data demonstrate that many of these recommendations are not followed. For example, less than half (48\%) of all environmental remediation advice is implemented, ${ }^{25} 71 \%$ of pediatric asthma primary care visits are not kept, ${ }^{26} 79 \%$ of COPD patients fail to complete home exercise programs, ${ }^{27}$ and $30-55 \%$ do not use their home oxygen. ${ }^{28}$

\section{Types of Non-Adherence}

Patients' purposeful decisions not to initiate or continue with therapy are described as intentional non-adherence 29 and are largely driven by alternative health beliefs or a failure to find medical advice compelling. ${ }^{30-32}$ Unintentional non-adherence, on the other hand, has more to do with a misunderstanding of what is being asked of the patient, overly complex treatment regimens, or a lack of routines or reminders that would provide the structure for regular medication use. ${ }^{30,32}$ Unintentional non-adherence can be remedied with patient education, reminder systems or assistance with simplifying or routinizing medication use, such as tying medication dosing to customary daily behaviors like brushing teeth or eating meals. Intentional non-adherence is more challenging, as it requires trust in the advice and the advisor, as well as multi-component psycho-behavioral interventions, which are discussed later. Examples of intentional and unintentional non-adherence can be found in Table 1 .

\section{Dimensions of Adherence}

The World Health Organization ${ }^{8}$ identifies 5 factors that have the potential to contribute to non-adherence: socioeconomic, therapy-related, condition-related, health system-related, and patient-related factors. Illustrations of each factor are noted below, and additional examples can be found in Table 2.

\section{Socioeconomic Factors}

The primary socioeconomic factors influencing medication non-adherence are access to prescription benefits and out-of-pocket expenses. Without coverage, drugs are prohibitively costly for many, particularly respiratory medicines where generic drugs have not been available in the United States for years. A case in point is cost-related non-adherence that occurred following Medicare capping and increased out-of-pocket contributions. Although Part D was introduced to increase access to prescription drugs for seniors, most Medicare drug plans have a coverage gap (ie, a donut hole) that can cause significant financial distress for older patients. In addition, formulary tiers make some of the most efficacious drugs inaccessible. Affected seniors have responded to the donut hole by implementing cost-coping behaviors such as forgoing food and mortgage payments and resorting to stretching medication possession time by taking fewer doses and using prescription maintenance treatments only when symptomatic. ${ }^{33} \mathrm{Re}$ cently, a demonstration model of value-based insurance design was launched in 7 states to reduce cost-sharing by 
Table 2. Factors Affecting Non-Adherence

\begin{tabular}{|c|c|c|c|c|}
\hline Socioeconomic & Therapy-Related & Condition-Related & Health System- Related & Patient-Related \\
\hline $\begin{array}{l}\text { Cost of medicine } \\
\text { Access to prescription } \\
\text { benefits } \\
\text { Lack of social support }\end{array}$ & $\begin{array}{l}\text { Duration of treatment } \\
\text { Complexity of treatment regimen } \\
\text { Previous treatment failures } \\
\text { Frequent changes to treatment } \\
\text { Adverse effects (real and perceived) } \\
\text { Speed of symptom or disease } \\
\quad \text { remission to treatment }\end{array}$ & $\begin{array}{l}\text { Duration of illness } \\
\text { Severity and frequency of } \\
\text { symptoms } \\
\text { Relief of symptoms or } \\
\text { likelihood of disease } \\
\text { remission in response } \\
\text { to treatment }\end{array}$ & $\begin{array}{l}\text { Poor quality of patient-provider } \\
\text { communication or partnership } \\
\text { Lack of continuity of care } \\
\text { Excessive wait times for or at } \\
\text { appointments } \\
\text { Institutional racism in the } \\
\text { health care setting } \\
\text { Inadequate time for } \\
\text { consultations } \\
\text { Lack of follow-up }\end{array}$ & $\begin{array}{l}\text { Low or limited literacy } \\
\text { or health literacy } \\
\text { Lack of knowledge of } \\
\text { the disease and its } \\
\text { treatment } \\
\text { Distrust } \\
\text { Premature delegation } \\
\text { of disease } \\
\text { management from } \\
\text { parent to child } \\
\text { Cognitive impairment } \\
\text { Beliefs about treatment } \\
\text { or illness that are in } \\
\text { conflict with the } \\
\text { medical model } \\
\text { Lack of motivation } \\
\text { Lack of confidence } \\
\text { (self-efficacy) } \\
\text { Forgetfulness }\end{array}$ \\
\hline
\end{tabular}

$\overline{\text { Data from Reference } 8 \text {. }}$.

aligning patients' out-of-pocket costs with essential highvalue clinical services. This is expected to increase COPD medication adherence by $5-15 \% .33$

\section{Therapy-Related Factors}

Frequency, complexity, and length of treatment are some of the many treatment-related factors that may affect adherence to asthma and COPD medications. Because these are chronic conditions, patients are expected to take medications for the rest of their lives. Most respiratory patients require multiple drugs each day; many of these drugs require more than once-daily dosing.

Taking respiratory medications isn't as simple as swallowing the right pill at the right time of day. Unique to inhaled medications, if the administration technique is inaccurate, then the drug is not delivered to the lower respiratory tract and therefore results in unintentional non-adherence. Inhaled medications also require selecting the right drug for the clinical indication (eg, quick-relief vs maintenance therapies), precisely preparing the dose (eg, priming), using the correct administration technique (eg, hand-breath coordination, inspiratory flow) specific to the device being used (eg, pressurized metered-dose inhaler, dry powder inhaler, slow mist inhaler, nebulizer, spacers/ valved holding chambers).

Incorrect beliefs about inhaled medications also lead patients to make treatment errors. For example, when the speed with which a drug relieves symptoms (eg, shortacting bronchodilators) is perceived as a measure of po- tency, then their use can be mistakenly prioritized over controller medicines like ICS. Patients also have been known to mistakenly attribute systemic side effects to ICS or confuse corticosteroids with anabolic steroids. An inaccurate fear of developing a tolerance or addiction to ICS is not uncommon. ${ }^{31}$

\section{Condition-Related Factors}

Adherence to treatment for chronic conditions is often poorer than that seen with time-limited illnesses. In addition, although the severity of disease or intensity of symptom burden should be associated with increased medication adherence, asthma and COPD symptoms may not abate during periods of adherence nor intensify during periods of non-adherence. ${ }^{8}$ Without a reliable association between medication adherence and symptom relief or disease remission, respiratory conditions may not provide the necessary feedback mechanism to promote sustained adherence.

\section{Health System-Related Factors}

Lack of access to medications ${ }^{33}$ (eg, tiered formularies) and dissatisfaction with health care provider interactions ${ }^{30}$ are additional barriers to adherence in asthma and COPD. Seven of the 10 rules proposed to improve quality in health care in the Institute of Medicine's 2001 Crossing the Quality Chasm report ${ }^{34}$ focused on ways that disease outcomes can be improved by delivering patient-centered care. Pa- 
tient-centered care as is defined as "respectful of and responsive to individual patient preferences, needs and values and ensuring that patient values guide all clinical decisions." 34 Without enhanced patient-provider partnerships, non-adherence may not be recognized by the provider or may not be disclosed by the patient. This has important patient safety implications. If a respiratory exacerbation is not identified as resulting from non-adherence as opposed to worsening disease, then a patient may be exposed to unneeded intensification of therapies, like courses of systemic corticosteroids.

\section{Patient-Related Factors}

In addition to inadequate knowledge, forgetfulness, and a lack of motivation, there are other patient-related factors that may contribute to non-adherence, including mental health conditions, competing priorities (eg, food or safety), and limited health literacy.

\section{Ways to Measure Adherence}

Several approaches are used to measure respiratory medication adherence, each with distinct advantages and disadvantages. ${ }^{29,35}$ Biochemical measurement can objectively confirm drug intake, but is costly. A provider estimate and a patient self-report are inexpensive but subjective. Prescription data are unbiased and inexpensive, but these do not confirm drug intake. Electronic monitors are objective, but widespread use has been limited by different monitors being needed for each device type. However, as industry embraces smart technology, electronic monitors embedded in each delivery device may become the norm. Most importantly, however, none of these measures currently have the ability to differentiate between intentional and unintentional non-adherence or relate disease activity back to adherence. ${ }^{35}$

\section{Biochemical Measurement}

With the exception of obtaining blood levels of orally administered theophylline, direct biochemical monitoring of respiratory drug levels in blood, urine, or saliva is difficult due to limited systemic absorption of topical medications that comprise the vast majority of respiratory products. To be done accurately, this approach would require repeated measures, which is both impractical and costly.

\section{Provider Estimate}

Health care providers may have a gut feeling as to whether patients are taking their medication or not. However, provider estimates have been shown to be no better than guessing in terms of distinguishing between adherent and non- adherent subjects in studies of anti-tuberculosis treatment or use of asthma controllers. ${ }^{36,37}$ Provider bias is nearly uniformly in the direction of assuming more adherence rather than less. ${ }^{36,37}$

\section{Patient Self-Report}

As Hippocrates reminds us, patients can lie about taking medications, ${ }^{1}$ and when they do, they almost always overreport adherence. This is less often because patients are devious and deceitful, but more often because patients wish to avoid confrontation, are embarrassed by their failure to follow through with medical advice, or desire to be a "good" patient. ${ }^{38}$ What is not always appreciated is the extent to which patients will take actions to appear adherent. In one study, the greatest concordance between objective measures of adherence and self-report was seen when subjects admitted to non-adherence (using the inhaler less than once a day). In contrast, the greatest discordance was evident when the inhaler was reported as being used as prescribed ( $73 \%$ vs $15 \%$ ). Moreover, $14 \%$ of subjects in this trial activated their inhalers $>100$ times in a 3-h period in a deliberate attempt to appear adherent, a behavior known as dumping. ${ }^{39}$ The take-away from this may be that patients are more likely being truthful when they disclose non-adherence than when they declare they are adherent.

\section{Prescription Data}

Compared to other major diseases like heart disease, hypertension, and depression, medication possession rates for asthma and COPD are among the lowest. ${ }^{40}$ As described in Table 3, the medication possession rate is a widely accepted measure of adherence and is calculated by dividing the days' supply by days in the observation period, and multiplying by 100 to arrive at a percentage of time when medication is available to the patient. The reason for low medication possession rates in respiratory diseases may be due to clinicians failing to prescribe medications or due to patients failing to obtain initial prescriptions (primary non-adherence) or to refill prescriptions (secondary non-adherence). An example of provider failure to prescribe medications may explain why $40 \%$ of $>600,000$ children with asthma had no prescriptions for asthma medicine, and only $15 \%$ with an asthma medicine had been prescribed an ICS. ${ }^{41}$ Other studies have reported medication possession rates no higher than $50 \%$ for controllers in children ${ }^{42}$ and adults with asthma. ${ }^{43}$ Other studies have shown that approximately $50 \%$ of COPD patients use any COPD medications and that $70 \%$ of those who do use COPD medicine can be classified as non-adherent. ${ }^{19}$ In one study, medication possession rates were only $44 \%$ during the last year of life for subjects with COPD. ${ }^{20}$ Hos- 
Table 3. Measures of Medication Possession or Use

\begin{tabular}{|c|c|}
\hline Measure of Medication Possession/Refill & Calculation \\
\hline Medication possession rates & Days' supply divided by days in the observation period \\
\hline $\begin{array}{l}\text { Continuous measures of medication } \\
\text { acquisition }\end{array}$ & Cumulative days of medication obtained divided by total days to end of observation period \\
\hline Medication refill adherence & Total days supplied divided by total days observed, multiplied by 100 \\
\hline Proportion of days covered & Number of days in period covered divided by the total number of days in the period, multiplied by 100 \\
\hline Persistence & $\begin{array}{l}\text { Time in days from first claim to last claim (plus the days' supply of the last claim) considering the days } \\
\text { between refills }\end{array}$ \\
\hline $\begin{array}{l}\text { Continuous measure of medication } \\
\text { gaps }\end{array}$ & $\begin{array}{l}\text { Cumulative days without any medication over a series of intervals divided by the total days from the } \\
\text { beginning to the end of the time period }\end{array}$ \\
\hline New prescription medication gap & $\begin{array}{l}\text { Time between date the medication was first prescribed until the end of follow-up, switch to an alternate } \\
\text { therapy, or medication is discontinued }\end{array}$ \\
\hline Discontinuation & A defined number of days after exhaustion of the days' supply from the previous dispensing \\
\hline
\end{tabular}

pital admissions rates are lowest 44 and survival rates highest ${ }^{44,45}$ among adherent COPD patients. Table 3 lists common prescription possession and use measures, as well as how these are calculated.

\section{Electronic Monitors and Smart Technology}

Add-on transferable electronic monitors were originally developed to measure adherence for research purposes. With the advent of newer, sophisticated, so-called smart technologies, embedded and connected devices aspire to do more than just measure adherence: they can serve as reminder systems, create trackable data points for patients and clinicians to interpret, and entrain geographical positioning and air quality data to identify triggers and location of medication use. Perhaps most importantly, they seek to do what other measures of adherence have not been able to do to date, which is to connect measures of disease control with adherence. ${ }^{35}$

Electronic Monitors. Add-on electronic monitors were initially relatively crude devices capable of indicating only if dose actuation occurred on a specific date (eg, Doser, MEDITRACK, Easton, MA) and hour (eg, Nebulizer Chronolog, MedTrac Technologies, Lakewood, CO), but they have evolved over time to discern whether a dose was taken using microphones or measures of flow (eg, SmartMist, Aradigm, Hayward, CA MDILog, Medtrac Technologies, and INCA, Vitalograph, Buckingham, England). ${ }^{46}$ Devices have also been produced to measure specific dry powder delivery systems (eg, Turbuhaler and Diskus) ${ }^{46}$ and to signal that doses are due by beeping (eg, Doser), ringing (eg, SmartTrack, Adherium, San Mateo, CA), or glowing (eg, CareTRx, Teva, Amsterdam, the Netherlands). With the exception of the Doser, which is available for consumer purchase, most electronic monitors were designed to measure adherence in clinical trials.
Smart Technology. With the cost associated with smart technology no longer an impediment to wide scale production, and with Bluetooth-enabled smartphones offering data aggregation in the cloud and direct interface with electronic health platforms, pharmaceutical companies are moving ahead with embedded sensing and connectable systems in their inhaled medication delivery devices. This is expected to offer patients and clinicians the opportunity to discover personal patterns of medication use and symptoms that otherwise might not have been discernible. It also offers insurers and researchers the opportunity to learn from aggregated population health data (ie, big data).

While smart devices can help monitor adherence, they will likely cost more, at least initially, than conventional unconnected inhaled delivery systems. In addition, the maximum benefit may only be derived from smart inhalers connected to the cloud, access that for many may be costprohibitive or intermittent as low-income consumers often rely on pay-as-you-go text and data-access plans. This smart future will therefore force payers to reconsider the cost of covering access in light of the value that the new devices offer in terms of supported management of certain high-risk populations.

To be accepted by patients, however, these integrated devices must be intuitive to use and must provide digestible bites of actionable and relevant data when the patient wants it. Most importantly, if adherence is to be measured, patients must want to opt in and to set limits on how closely they are monitored, fearing repercussions for being identified as non-adherent. ${ }^{47}$

Although $90 \%$ of asthma patients state that they were willing to carry and use a connected device, ${ }^{48}$ non-persistence with electronic monitors has been documented. In a study of propeller technologies, $15 \%$ of adults with asthma stopped monitoring in their first month, and $43 \%$ had stopped monitoring by year's end. ${ }^{49}$ In a study of 89 children with asthma, rates of device malfunction and loss 
were much higher in the group randomized to use a device for adherence tracking compared to those whose data were not reviewed for adherence ( $35 \%$ vs $8 \%$ ), leading the authors to conclude that some of the devices were deliberately broken or lost..$^{50}$

\section{Strategies to Improve Adherence}

\section{Strategies to Reduce Unintentional Non-Adherence}

As described earlier, most unintentional non-adherence can be attributed to not having an understanding of the disease or treatment regimen or not having structures in place to remind the individual that a dose is due. To that end, strategies to address unintentional non-adherence focus on patient education, simplification of regimens, and structures for remembering medication.

Education. Asthma education is 1 of 4 critical components of the national asthma guidelines, and a large number of clinical trials have demonstrated asthma education improves ICS adherence. ${ }^{17,51}$ Unfortunately, not all patients receive asthma education. Healthy People 2020 sought to increase the proportion of individuals receiving formal asthma education from 8\% to 30\%, but as of 2007 only $12 \%$ of adults reported having received asthma selfmanagement education. ${ }^{52,53}$ More children than adults report receiving asthma education; adults with private insurance, compared to those with Medicaid or no insurance, are more likely to report receiving self-management education. ${ }^{53}$ Less is known about the role of COPD education on adherence. One Canadian study demonstrated that subject education increased the use of COPD drugs, ${ }^{54}$ although inhaler instruction has been less effective in COPD subjects compared to asthma subjects. ${ }^{30}$

Reminders. Both text messaging and audiovisual reminders are effective short-term approaches to improving ICS adherence. ${ }^{17}$ Whether reminders can sustain adherence in the long term has not been established, and there is concern that frequent reminders may become a nuisance to patients. ${ }^{55}$ Moreover, health reminders delivered to smartphones may get crowded out by banners and alerts from news sites and social networking platforms, creating in essence a new type of alarm fatigue. Dose reminders, as part of a multi-component intervention, were effective in improving adherence to COPD medicines in a small randomized trial. ${ }^{56}$

Routines. For many chronic conditions, pill boxes are used to organize medications and to serve as visual reminders of use. However, these boxes do not accommodate inhaled devices, so patients with asthma and COPD resort to keeping their medication in view or in the same location in the home, integrating medication use into morning or evening routines, or carrying their controller medications with them. ${ }^{57-60}$

Simplifying Medication Regimens. Complex regimens decrease adherence across a variety of diseases. ${ }^{8}$ For example, with each additional incremental dose per day, from once a day to 4 times a day, adherence drops (43\% vs $37 \%$ vs $30 \%$ vs $23 \%$, respectively) in COPD. ${ }^{61}$ Decreasing the number of drugs or the number of daily doses is often a first, and effective, step in improving ICS adherence and COPD drug use. ${ }^{17,62}$ To that end, combination inhalers offer an easy way to simplify the number of drugs and doses per day.

\section{Innovative Strategies to Reduce Intentional Non-Adherence}

Despite knowledge of asthma and its management, some patients still do not find medical advice compelling or hold deeply entrenched beliefs that conflict with treatment recommendations. ${ }^{13,31}$ Because these barriers are complex and indelible, and because strategies focused on unintentional non-adherence are ineffective in these contexts, novel, multi-component, patient-centered, psychotherapeutic approaches have been proposed, including coaching, use of navigators/advocates, shared decision-making, and motivational interviewing. The application of these approaches to asthma and COPD are detailed below.

Coaching. Interventions focused on empowering patients to set and achieve health goals of their own making is the central feature of coaching, which is also described as health or wellness coaching. ${ }^{63}$ As opposed to patient education that is more disease- and curriculum-focused, coaching incorporates health promotion more broadly, is more active, and is more patient-directed. Coaches typically have advanced training in behavioral sciences, with a focus on behavioral change theory, communication, and motivational skills. A final differentiating point is that, compared to patient educators who have time-limited relationships with their clients, coaches typically have ongoing, or even enduring, relationships with patients. ${ }^{63}$

Although coaching can be used to supplement or complement patient education to address unintentional nonadherence, it is time- and labor-intensive. Therefore, most trials have utilized coaching in asthma and COPD populations known or suspected to have some degree of intentional non-adherence. Coaching has been shown to improve inhaler technique in adults with asthma, reduce asthma symptoms and acute health care utilization in children, and enhance quality of life of parents of asthmatic children. ${ }^{64-66}$ Coaching directed at parents of chil- 
dren with asthma who present to the emergency department demonstrated improved attendance at primary care visits, but not subsequent emergency department visits, in one trial ${ }^{67}$ but not in another. ${ }^{68}$ In a small trial in subjects with COPD, subject education combined with coaching reduced unscheduled office visits and improved subjects' quality of life. ${ }^{69}$ Adherence was not measured in any of these trials. One small study of subjects with COPD who received an electronic activity coach measured adherence to a home-exercise program that consisted of a smart accelerometer and receipt of daily scripted motivational messages; in this trial, only $21 \%$ of subjects were adherent. ${ }^{27}$

Navigators/Advocates. Originating decades ago, patient navigators and patient advocates were nurses and other highly trained lay individuals who guided cancer patients through complex payer and health care systems to obtain multiple consultations and diagnostic tests so that they could make informed decisions about their cancer treatment. The critical components of this skill set included education, support, and care coordination across the care continuum (home, acute care, primary care)..$^{70}$ Like coaching, navigators may be effective in addressing unintentional non-adherence, but because it is a costly and labor-intensive approach, most trials have focused on populations with suboptimal clinical outcomes due, in part, to intentional non-adherence. This model has more recently been applied to adults with asthma ${ }^{71-73}$ and COPD, ${ }^{70}$ but its effectiveness it unknown either because of methodological limitations ${ }^{70}$ or because evaluation is ongoing. ${ }^{73}$

Shared Decision-Making. Historically, medicine has taken a paternalistic approach to patient-provider relationships, with clinicians deciding what is best for the patient based on their expertise and the scientific evidence. This evolved to an informative model of care in which providers informed patients about why a treatment was recommended, later adding an interpretative approach that helped patients find their own preferences for care. A more advanced and deliberative model of care, ${ }^{74}$ which includes an explicit exploration of both provider and patient treatment preferences, is purported to help reconcile differences, leading to mutually agreed-upon, higher-quality decisions that best match patients' needs with evidence-based recommendations. ${ }^{13}$ When providers understand patient preferences for disease management, then they can facilitate discussion of the risks and merits of treatment options and entertain these options jointly, an approach described as shared decision-making. ${ }^{75}$ In this model of care, things patients value are held in equal regard as what providers value, ${ }^{13}$ and this approach has been shown to improve medication adherence by subjects with chronic disease. ${ }^{76-79}$

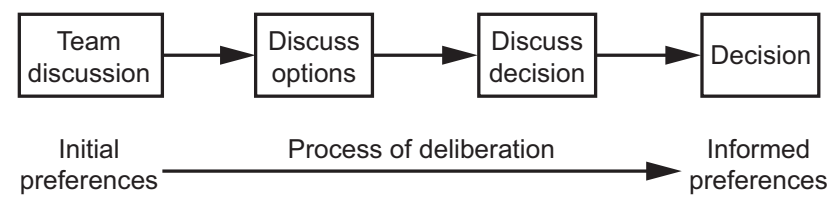

Fig. 1. Schematic of Elwyn and colleagues' simplified approach to thinking about shared decision-making. Adapted from Reference 75.

Figure 1 depicts a simplified approach to shared decisionmaking in which options (pros and cons) are discussed and patients' treatment preferences are seen as integral to arriving at an informed decision. ${ }^{75}$

The effectiveness of shared decision-making approaches on improved asthma medication adherence and other markers of disease management has been studied. In randomized, controlled trial of 612 adults, those who received an intensive shared decision-making intervention (multiple lengthy visits with highly-trained interventionists) improved ICS adherence, asthma-related quality of life, asthma control, lung function, and reduced quick relief bronchodilator use and acute health care utilization. ${ }^{79} \mathrm{~A}$ pragmatic extension of this trial to 30 primary care sites is under way. ${ }^{80}$ In pediatric asthma, parents who used a shared decision-making portal reported fewer absences from work and fewer exacerbations in their children. ${ }^{81}$

Motivational Interviewing/Enhancement. Motivational interviewing is a specific microcounseling approach developed by clinical psychologists Miller and Rollnick as part of a screening, brief intervention, and referral to treatment strategy for problem drinking and drug use. ${ }^{82}$ Motivational interviewing recognizes that patients are often ambivalent about behavior change and engages them to resolve their indifference by harnessing their intrinsic motivation to reach personal goals. The motivational interviewer rolls with resistance rather than confronting or challenging the patient, is empathetic to and accepting of patients' healthy and unhealthy decisions, and shows genuine concern and compassion. ${ }^{82}$

As shown in Figure 2, motivational interviewing consists of 4 steps: engaging, focusing, evoking, and planning. ${ }^{75}$ The goal of the first step (engaging) is to establish a therapeutic alliance with the patient. In the second step (focusing), a candid conversation helps draw a connection between current behaviors and the benefits of future behavioral change. In the third step (evoking), attempts to enhance patients' motivation are made using motivational interviewing techniques such as collaboration, empathy, concern, and acceptance of ambivalence. In this step, beliefs regarding the benefits and negative sequelae of their current approaches (pros and cons) are explored. In the final step (planning), options are jointly considered, and there is an attempt to build consensus around behavioral 


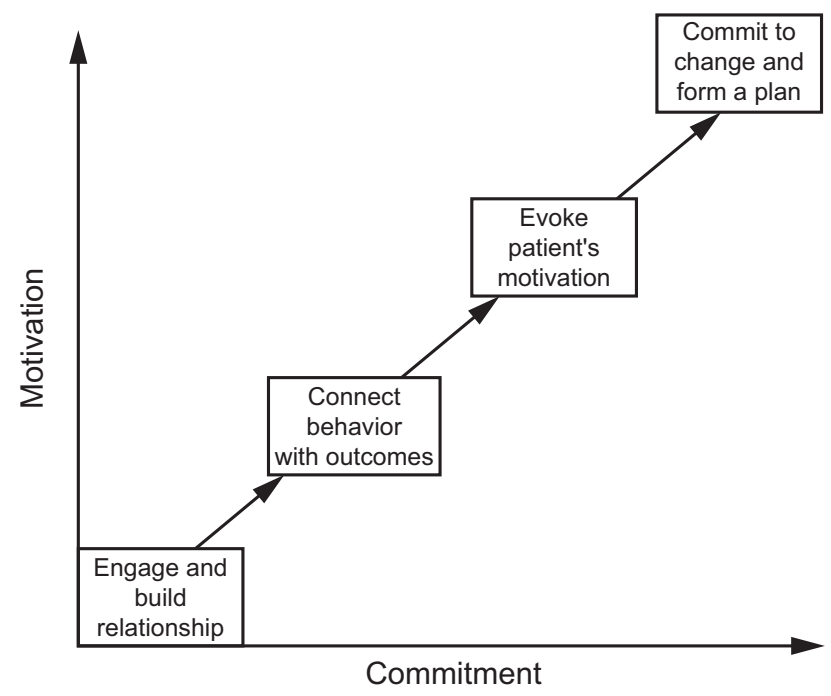

Fig. 2. Steps in motivational interviewing. Adapted from Reference 75.

change. ${ }^{75}$ The term motivational enhancement has recently been used to describe interventions that adhere to some, but not all, motivational interviewing tenets or that reflect variations from prescribed motivational interviewing protocols.

There are several small trials of motivational interviewing as a component of multi-factorial interventions in asthma and COPD populations. In a randomized, controlled trial of 146 subjects with COPD, those who received motivational interviewing as part of a comprehensive disease management strategy (ie, disease information, medication reminders, and inhaler education) had higher rates of medication adherence. ${ }^{56}$ However, due to the bundling of interventions, it isn't possible to determine what attributes or interventions in this trial were responsible for the improved adherence rates.

Other motivational interviewing studies have not measured adherence. A randomized, controlled trial of 43 practices that included 1,634 COPD subjects examined the effect of training clinicians in motivational interviewing, with a specific focus on the shared decision-making component. This approach did not have added value above the self-management training the practices had already received $^{83}$ and was not cost-effective. ${ }^{84}$ As a component of multi-factorial asthma interventions, motivational interviewing reduced children's exposure to environmental tobacco smoke 85 and improved symptom-days and restricted activity days in adolescents enrolled in a Web-based asthma self-management program. ${ }^{86}$ In a subset of these 422 teens, those who met the diagnostic criteria for rebelliousness also experienced reduced symptom-nights and school absences. ${ }^{86}$

\section{Summary}

In this article, adherence has been defined and methods for measuring adherence have been detailed. Factors related to disease, treatment, health care systems, medication cost and access, as well as patient-specific attributes associated with suboptimal adherence have been explicated. By differentiating intentional from unintentional non-adherence, clinicians will be better able to match intervention strategies to the underlying cause of non-adherence. A review of the literature identified novel psychotherapeutic interventions to address intentional non-adherence that, while still in development, offer clinicians some early signals as to approaches that may be successful in managing the most complex and challenging adherence issues in the future. Large, rigorously designed trials that focus on the evaluation of individual components' effects on adherence are needed before greater dissemination and implementation of these strategies can be recommended.

Some questions remain. Why should clinicians try to improve adherence? To achieve disease control and improve patient safety, such as reduced morbidity and reduced exposure to unnecessary treatment intensification, adherence must be improved. How is improved adherence to be accomplished? To date, patients have borne an unequal portion of blame for non-adherence because much of non-adherence is unintentional. As such, patients need to be supported, not censured. This support must come from the health professionals who care for them, and these health professionals must be trained in adherence and knowledgeable about effective tailored adherence interventions. This will not fall to one individual or to one approach. Rather, it will require a team using multidimensional approaches that address all the factors that contribute to nonadherence. This is well worth doing because increasing the effectiveness of adherence interventions may have a far greater impact on the health of the population than any improvement in specific medical treatments. ${ }^{8}$

\section{REFERENCES}

1. Hippocrates. BrainyQuote.com. https://www.brainyquote.com/quotes/ quotes/h/hippocrate138975.html. Accessed August 3, 2017.

2. Ward BW, Schiller JS, Goodman RA. Multiple chronic conditions among US adults: a 2012 update. Prev Chronic Dis 2014;11:130389.

3. Centers for Disease Control. Asthma in the US: Growing every year. https://www.cdc.gov/vitalsigns/asthma/index.html. Accessed August $3,2017$.

4. National Institutes of Health. Chronic obstructive pulmonary disease (COPD). https://report.nih.gov/nihfactsheets/pdfs/chronicobstructive pulmonarydisease(nhlbi).pdf Accessed August 3, 2017.

5. World Health Organization. Chronic obstructive pulmonary disease. http://www.who.int/mediacentre/factsheets/fs315/en/ Accessed August 3, 2017.

6. Mäkelä MJ, Backer V, Hedegaard M, Larsson K. Adherence to inhaled therapies, health outcomes and costs in patients with asthma and COPD. Respir Med 2013;107(10):1481-1490. 
7. Nolte E, McKee M. Caring for people with chronic conditions: A health system perspective. World Health Organization, 2008. http://www. euro.who.int/_data/assets/pdf_file/0006/96468/E91878.pdf. Accessed August 3, 2017.

8. World Health Organization. Adherence to long-term therapies: Evidence for action. http://apps.who.int/medicinedocs/pdf/s4883e/ s4883e.pdf. Accessed August 3, 2017.

9. Aronson JK. Compliance, concordance, adherence. Br J Clin Pharmacol 2007;63(4):383-384.

10. Eakin MN, Bilderbeck A, Boyle MP, Mogayzel PJ, Riekert KA. Longitudinal association between medication adherence and lung health in people with cystic fibrosis. J Cys Fibros 2011;10(4): 258-264.

11. Rapoff MA. Management of adherence and chronic rheumatic disease in children and adolescents. Best Pract Res Clin Rheumatol 2006;20:301-314.

12. Borus JS, Laffel L. Adherence challenges in the management of type 1 diabetes in adolescents: Prevention and intervention Curr Opin Pediatr 2010;22(4):405-411.

13. George, M. Integrative medicine is integral to providing patientcentered care. Ann Allergy Asthma Immunol 2015;114:261-264.

14. Nieuwlaat R, Wilczynski N, Navarro T, Hobson N, Jeffery R, Keepanasseril A, et al. Interventions for enhancing medication adherence. Cochrane Database Syst Rev 2014;20(11):CD000011.

15. McDonald HP, Garg AX, Haynes RB. Interventions to enhance patient adherence to medication prescriptions: Scientific review. JAMA 2002;288:2868-2879.

16. Okeke CO, Quigley HA, Jampel HD, Ying G, Plyler RJ, Jiang Y, Friedman DS. Interventions improve poor adherence with once daily glaucoma medications in electronically monitored patients. Ophthalmology 2009;116(12):2286-2293.

17. Normansell R, Kew KM, Stovold E. Interventions to improve adherence to inhaled steroids for asthma. Cochrane Database Syst Rev 2017;18(4):CD012226.

18. Sulaiman I, Cushen B, Greene G, Seheult J, Seow D, Rawat F, et al. Objective assessment of adherence to inhalers by patients with chronic obstructive pulmonary disease. Am J Respir Crit Care Med 2017; 195(10):1333-1343

19. Mueller S, Wilke T, Bechtel B, Punekar YS, Mitzner K, Virchow JC. Non-persistence and non-adherence to long-acting COPD medication therapy: A retrospective cohort study based on a large German claims dataset. Respir Med 2017;122:1-11.

20. Jung E, Pickard S, Salmon JW, Bartle B, Lee TA. Medication adherence and persistence in the last year of life in COPD patients. Resp Med 2009;103(4):525-534.

21. DiMatteo MR. Variations in patients' adherence to medical recommendations: A quantitative review of 50 years of research. Med Care 2004;42(3):200-209.

22. Bollinger ME, Mudd KE, Boldt A, Hsu VD, Tsoukleris MG, Butz AM. Prescription fill patterns in underserved children with asthma receiving subspecialty care. Ann Allergy Asthma Immunol 2013; 111(3):185-189.

23. Fan VS, Gylys-Colwell I, Locke E, Sumino K, Nguyen HQ, Thomas RM, Magzamen S. Overuse of short-acting beta-agonist bronchodilators in COPD during periods of clinical stability. Resp Med 2016; 116:100-106.

24. Wu AC, Butler MG, Li L, Fung V, Kharbanda EO, Larkin EK, et al. Primary adherence to controller medications for asthma is poor. Ann Am Thorac Soc 2015;12(2):161-166.

25. Centers for Disease Control. Asthma in the US: Growing every year. https://www.cdc.gov/vitalsigns/pdf/2011-05-vitalsigns.pdf. Accessed August 19, 2017.

26. McGovern CM, Redmond M, Arcoleo K, Stukus DR. A missed primary care appointment correlates with a subsequent emergency department visit among children with asthma. J Asthma 2017;54(9): 977-982.

27. Tabak M, Brusse-Keizer M, van der Valk P, Hermens H, Vollenbroek-Hutten M. A telehealth program for self-management of COPD exacerbations and promotion of an active lifestyle: A pilot randomized controlled trial. Int J Chron Obstruct Pulmon Dis 2014;9:935-944.

28. Katsenos S, Constantopoulos SH. Long-term oxygen therapy in COPD: Factors affecting and ways of improving patient compliance. Pulm Med 2011;2011:325-362.

29. Rau JL. Determinants of patient adherence to an aerosol regimen. Respir Care 2005;50(10):1346-1356.

30. Restrepo RD, Alvarez MT, Wittnebel LD, Sorenson H, Wettstein R, Vines DL, et al. Medication adherence issues in patients treated for COPD. Int J Chron Obstruct Pulmon Dis 2008;3(3):371-384.

31. George M, Topaz M, Rand, C, Sommers MS, Glanz K, Pantalon $\mathrm{MV}$, et al. Inhaled corticosteroid beliefs, complementary and alternative medicine and uncontrolled asthma in urban minority adults. $\mathrm{J}$ Allergy Clin Immunol 2014;134:1252-1259.

32. Clifford S, Barber N, Horne R. Understanding different beliefs held by adherers, unintentional non-adherers, and intentional non-adherers: Application of the Necessity-Concerns Framework. J Psychosom Res 2008;64:41-46.

33. Fendrick AM, Oesterle SL, Lee HM, Padaley P, Eagle T, Chernew M., et al. Incorporating value-based insurance design to improve chronic disease management in the Medicare Advantage program 2016. http://vbidcenter.org/wp-content/uploads/2016/08/MA-WhitePaper_final-8-16-16.pdf. Accessed August 17, 2017.

34. Institute of Medicine (IOM). Crossing the quality chasm: A new health system for the 21st century. Washington, DC: National Academy Press; 2001.

35. van Boven JFM, Trappenburg JCA, van der Molen T, Chavannes $\mathrm{JNH}$. Towards tailored and targeted adherence assessment to optimise asthma management. NPJ Prim Care Respir Med 2015;25: 15046.

36. MacIntyre CR, Goebel K. Patient knows best: Blinded assessment of nonadherence with antituberculous therapy by physicians, nurses, and patients compared with urine drug levels. Prev Med 2005;40(1): 41-45.

37. Sherman J, Hutson A, Baumstein S, Hendeles L. Telephoning the patient's pharmacy to assess adherence with asthma medications by measuring refill rate for prescriptions. J Pediatr 2000;136:532-536.

38. Palmieri JJ, Stern TA. Lies in the doctor-patient relationship. Prim Care Companion J Clin Psychiatry 2009;11(4):163-168.

39. Rand CS, Wise RA, Nides M, Simmons MS, Bleecker ER, Kusek $\mathrm{JR}$, et al. Metered-dose inhaler adherence in a clinical trial. Am Rev Resp Dis 1992;146(6):1559-1564.

40. Rolnick SJ, Pawloski PA, Hedblom BD, Asche SE, Bruzek RJ. Patient characteristics associated with medication adherence. Clin Med Res 2013;11(2):54-65.

41. Arellano FM, Arana A, Wentworth CE, Vidaurre CF, Chipps BE. Prescription patterns for asthma medications in children and adolescents with health care insurance in the United States. Pediatr Allergy Immunol 2011;22(5):469-476.

42. Engelkes M, Janssens HM, de Jongste JC, Sturkenboom MC, Verhamme KM. Prescription patterns, adherence and characteristics of non-adherence in children with asthma in primary care. Pediatr Allergy Immunol 2016;27(2):201-208.

43. Feehan M, Ranker L, Durante R, Cooper DK, Jones GJ, Young DC, Munger MA. Adherence to controller asthma medications: 6-month prevalence across a US community pharmacy chain. J Clin Pharm Ther 2015;40:590-593. 
44. Vestbo J, Anderson JA, Calverley PM, Celli B, Ferguson GT, Jenkins C, Knobil K, et al. Adherence to inhaled therapy, mortality and hospital admission in COPD. Thorax 2009;64(11):939-943.

45. Belleudi V, Di Martino M, Cascini S, Kirchmayer U, Pistelli R, Formoso G, et al., on behalf of the OUTPUL Study Group. The impact of adherence to inhaled drugs on 5-year survival in COPD patients: A time dependent approach. Pharmacoepidemiol Drug Saf 2016;25(11):1295-1304.

46. Kikidis D, Konstantinos V, Tzovaras D, Usmani OS. The digital asthma patient: The history and future of inhaler based health monitoring devices. J Aeros Med Pulm Drug Deliv 2016;29(3):219-232.

47. Rackley J. Smart inhalers: Pros and cons. Health Central. https:// www.healthcentral.com/article/smart-inhalers-pros-and-cons. Accessed August 20, 2017.

48. K. Votis, A. Lalos, K. Moustakas, D. Tzovaras. Analysis, modelling and sensing of both physiological and environmental factors for the customized and predictive self-management of asthma. In Proc 6th Panhellenic Conf of Biomedical Technology, held May 68, 2015, in Athens, Greece. http://www.myaircoach.eu/myaircoach/sites/default/ files/publications/votis_et_al_elevit_2015.pdf. Accessed August 20, 2017.

49. Merchant RK, Inamdar R, Quade RC. Effectiveness of population health management using the Propeller Health asthma platform: A randomized clinical trial. J Allergy Clin Immunol Pract 2016;4(3): 455-463.

50. Morton RW, Elphick HE, Rigby AS, Daw WJ, King DA, Smith LJ, Everard ML. STAAR: A randomised controlled trial of electronic adherence monitoring with reminder alarms and feedback to improve clinical outcomes for children with asthma. Thorax 2017;72(4):347354.

51. Expert Panel Report 3 (EPR-3). National Asthma Education and Prevention Program. Guidelines for the diagnosis and management of asthma. NIH pub no 07-4051. Bethesda, MD: National Heart, Lung, and Blood Institute, National Institutes of Health. 2007 https://www. nhlbi.nih.gov/health-pro/guidelines/current/asthma-guidelines. Accessed August 22, 2017.

52. Healthy People 2020. Office of Disease Prevention and Health Promotion 2010. https://www.healthypeople.gov/. Accessed August 22, 2017.

53. Centers for Disease Control and Prevention. Vital signs: Asthma prevalence, disease characteristics, and self-management education: United States, 2001-2009. MMWR 2011;60(17):547-552.

54. Sari N, Osman M. The effects of patient education programs on medication use among asthma and COPD patients: A propensity score matching with a difference-in-difference regression approach. BMC Health Serv Res 2015;15:332-341.

55. Dennison L, Morrison L, Conway G, Yardley L. Opportunities and challenges for smartphone applications in supporting health behavior change: qualitative study. J Med Internet Res 2013;15(4):e86.

56. Leiva-Fernández J, Leiva-Fernández F, García-Ruiz A, Prados-Torres D, Barnestein-Fonseca P. Efficacy of a multifactorial intervention on therapeutic adherence in patients with chronic obstructive pulmonary disease (COPD): A randomized controlled trial. BMC Pulm Med 2014;14:70.

57. Brooks TL, Leventhal H, Wolf MS, O'Conor R, Morillo J, Martynenko M, et al. Strategies used by older adults with asthma for adherence to inhaled corticosteroids. J Gen Intern Med 2014;29(11): 1506-1512.

58. George M, Freedman TG, Norfleet AL, Feldman HI, Apter AJ. Qualitative research enhanced understanding of patients' beliefs: Results of focus groups with low-income urban African American adults with asthma. J Aller Clin Immun 2003;111:967-973.

59. Bruzzese JM, Idalski Carcone A, Lam P, Ellis DA, Naar-King S. Adherence to asthma medication regimens in urban African Amer- ican adolescents: Application of self-determination theory. Health Psychol 2014;33(5):461-464.

60. George J, Kong DC, Stewart K. Adherence to disease management programs in patients with COPD. Int J Chron Obstruct Pulmon Dis 2007;2(3):253-262.

61. Toy EL, Beaulieu NU, McHale JM, Welland TR, Plauschinat CA, Swensen A, et al. Treatment of COPD: Relationships between daily dosing frequency, adherence, resource use, and costs. Respir Med 2011;105(3):435-444.

62. Sanduzzi A, Balbo P, Candoli P, Catapano GA, Contini P, Mattei A, et al. COPD: Adherence to therapy. Multidiscip Respir Med 2014; 9(1):60-69.

63. Wolever RQ, Simmons LA, Sforzo GA, Dill D, Kaye M, Bechard $\mathrm{EM}$, et al. A systematic review of the literature on health and wellness coaching: Defining a key behavioral intervention in healthcare. Glob Adv Health Med 2013;2(4):38-57.

64. Crane MA, Jenkins CR, Goeman DP, Douglass JA. Inhaler device technique can be improved in older adults through tailored education: findings from a randomised controlled trial. NPJ Prim Care Respir Med 2014;24:14034

65. Garbutt JM, Yan Y, Highstein G, Strunk RC. A cluster-randomized trial shows telephone peer coaching for parents reduces children's asthma morbidity. J Allergy Clin Immunol 2015;135(5): $1163-1170$

66. Garbutt JM, Banister C, Highstein G, Sterkel R, Epstein J, Bruns J, et al. Telephone coaching for parents of children with asthma: impact and lessons learned. Arch Pediatr Adolesc Med 2010;164(7):625630 .

67. Nelson KA, Highstein GR, Garbutt J, Trinkaus K, Fisher EB, Smith $\mathrm{SR}$, et al. A randomized controlled trial of parental asthma coaching to improve outcomes among urban minority children. Arch Pediatr Adolesc Med 2011;165(6):520-526.

68. Smith SR, Jaffe DM, Highstein G, Fisher EB Trinkaus KM, Strunk RC. Asthma coaching in the pediatric emergency department. Acad Emerg Med 2006;13(8):835-839.

69. Bourbeau J, Farias R, Li PZ, Gauthier G, Battisti L, Chabot V, et al. The Quebec Respiratory Health Education Network: Integrating a model of self-management education in COPD primary care. Chron Respir Dis 2017 [Epub ahead of print] doi: 10.1177/1479972317723237.

70. Dajczman E, Robitaille C, Ernst P, Hirsch AM, Wolkove N, Small $\mathrm{D}$, et al. Integrated interdisciplinary care for patients with chronic obstructive pulmonary disease reduces emergency department visits, admissions and costs: A quality assurance study. Can Respir J 2013; 20(5):351-356

71. Apter AJ, Wan F, Reisine S, Bogen DK, Rand C, Bender B, et al. Feasibility, acceptability and preliminary effectiveness of patient advocates for improving asthma outcomes in adults. J Asthma 2013; 50(8):850-860

72. Black HL, Priolo C, Akinyemi D, Gonzalez R, Jackson DS, Garcia L, et al. Clearing clinical barriers: Enhancing social support using a patient navigator for asthma care. J Asthma 2010;47:913-919.

73. Apter AJ, Morales KH, Han X, Perez L, Huang J, Ndicu G, et al. A patient advocate to facilitate access and improve communication, care, and outcomes in adults with moderate or severe asthma: Rationale, design, and methods of a randomized controlled trial. Contemp Clin Trials 2017;56:34-45.

74. Emanuel EJ, Emanuel LL. Four models of the physician-patient relationship. JAMA 1992;267:2221-2226.

75. Elwyn G, Dehlendorf C, Epstein RM, Marrin K, White J, Frosch DL. Shared decision making and motivational interviewing: Achieving patient-centered care across the spectrum of health care problems. Ann Fam Med 2014;12(3):270-275.

76. Saheb Kashaf M, McGill ET, Berger ZD. Shared decision-making and outcomes in type 2 diabetes: A systematic review and meta- 
analysis. Patient Educ Couns 2017 [Epub ahead of print] doi: 10.1016/ j.pec.2017.06.030.

77. Schneider J, Kaplan SH, Greenfield S, Li W, Wilson IB. Better physician-patient relationships are associated with higher reported adherence to antiretroviral therapy in patients with HIV infection. J Gen Intern Med 2004;19(11):1096-1103.

78. Cooper LA, Roter DL, Carson KA, Bone LR, Larson SM, Miller ER, et al. A randomized trial to improve patient-centered care and hypertension control in underserved primary care patients. J Gen Intern Med 2011;26(11):1297-1304.

79. Wilson SR, Strub P, Buist AS, Knowles SB, Lavori PW, Lapidus J, et al. Shared treatment decision making improves adherence and outcomes in poorly controlled asthma. Am J Respir Crit Care Med 2010;181(6):566-577.

80. Tapp H, McWilliams A, Ludden T, Kuhn L, Taylor Y, Alkhazraji T, et al. Comparing traditional and participatory dissemination of a shared decision making intervention (ADAPT-NC): A cluster randomized trial. Implement Sci 2014;9:158.

81. Fiks AG, Mayne SL, Karavite DJ, Suh A, O'Hara R, Localio AR, et al. Parent-reported outcomes of a shared decision-making por- tal in asthma: A practice-based RCT. Pediatrics 2015;135(4):e965e973.

82. Miller WR, Rollnick. Motivational interviewing: Helping people change. 3rd ed. New York: Guilford Press; 2013.

83. Kennedy A, Bower P, Reeves D, Blakeman T, Bowen R, ChewGraham C, et al. Implementation of self management support for long term conditions in routine primary care settings: Cluster randomised controlled trial. BMJ. 2013;346:f2882.

84. Boland MR, Kruis AL, Tsiachristas A, Assendelft WJ, Gussekloo J, Blom CM, et al. Cost-effectiveness of integrated COPD care: The RECODE cluster randomised trial. BMJ Open 2015;5(10): e007284.

85. Baxi R, Sharma M, Roseby R, Polnay A, Priest N, Waters E, et al. Family and carer smoking control programmes for reducing children's exposure to environmental tobacco smoke. Cochrane Database Syst Rev 2014;3:CD001746.

86. Joseph CL, Ownby DR, Havstad SL, Saltzgaber J, Considine S, Johnson D, et al. Evaluation of a web-based asthma management intervention program for urban teenagers: Reaching the hard to reach. J Adolesc Health 2013;52(4):419-426.

\section{Discussion}

Lugogo: I struggle with how to really get at non-adherence in the clinic, and I think a tool of some kind would be nice to have. Are there any questionnaires or things you could give to the patient while they're completing their asthma control questionnaires that they could fill out that says I'm adherent or I'm non-adherent and maybe gets at some of the reasons for non-adherence?

George: There are some tools that have been developed by industry as part of clinical trials that are not really available for mass market. I use the Medication Adherence Report Scale for Asthma, which correlates with both objective measures of adherence as well as pharmacy refill data. Jerry Krishnan found one question predicted non-adherence and showed that, within $7 \mathrm{~d}$ of leaving the hospital, subjects stopped their oral steroids and ICS. ${ }^{1}$ The one question that identified who was likely to stop their ICS and oral steroids after an acute exacerbation for asthma was simply, "Have you missed at least 1 dose of your ICS in the last week?" That's a pretty simple question to ask. And if they admit that they missed at least 1 dose, they were likely to have missed $50 \%$ or more of their doses.
Wise: Wow. I used to think that economics was the dismal science, but now it appears that behavioral nursing is.

George: I always wanted to care for the patients that nobody else wanted. I wanted the patient who won't do anything you tell them, that's who I love to work with.

Wise: I have a couple questions, one is this donut hole. It seems to me that most of my COPD patients have pretty much the same regimen of $\$ 200-\$ 300$ drugs per month plus whatever their copay is-and they reach their donut hole in July or August. Is there any evidence that there's a seasonality effect in terms of adherence?

George: I don't know that we have that data. I do know that patients in the donut hole have clearly been shown to demonstrate some of the patterns we talked about yesterday: they take only their morning dose and not their evening dose, or go to every other day, or based on symptoms only. We do know those 3 patterns. We also know that patients are more adherent immediately before and after office visits.

Wise: We dread the summer because we have to work around that. The sec- ond thing that one could do is a little scale for the Juniper Score. I would recommend looking up Credit Karma because they have a little meter for your credit score and it's very motivating to look at it and see how you're doing.

George: We have pretty good data on this. There's a big information visualization group at Columbia, and they've shown that in HIV and caregivers of individuals with dementia that these tools motivate people to start to self-manage. ${ }^{2}$ They're helping me develop this, and they say that the meter is going well.

Wise: Right, it goes from green to yellow to red like a little speedometer. The third thing, and I know you appreciate this, is that the interface with the doctors is important too. I think most doctors hate to get the constant reminders we get from some of these systems.

George: Right, I focused on just patients here, but there is a wealth of information that we know. We haven't even talked about providers, just the patient side.

Wise: Engineers make these great devices, but they haven't figured out how to develop a useful and usable 
interface for patients and doctors. EPIC is an example of that.

George: And they don't co-produce them with either patients or health professionals. With the exception of MyAirCoach, who has done it, but their device isn't on the market yet.

Donohue: Maureen, that was a wonderful presentation. Payers cannot afford for non-adherence to be the driving mechanism for the addition or substitution of these drugs. So, that's one of the reasons I thought of that doesn't involve the patients, which I'm most concerned about, like you are. The FDA has become very interested in patient preference, and there's soon going to be a meeting on endobronchoscopic coils for COPD and emphysema. In the course of that, under the direction and in concert with the FDA, Research Triangle Institute has developed a quantitative tool—and it's quite brilliant - to show a patient a number of pictures like taking a shower, walking up the stairs (the things from $\mathrm{St}$ George's Questionnaire) and then you give them quantitatively the risk of the procedure. This procedure would be $1 \%$ risk for hemorrhage, or what have you, and then the patient makes their choice. I thought that was really something that might be really interesting to get the patient, the key person in the regulatory realm of everybody plus the FDA. We'll have to see how that goes, but it is all FDA directed.

George: These are decision aids that would be so helpful to have at a visit. I can see our work moving toward a decision aid that includes asthma risks.

Donohue: A big problem is why do people not adhere. Are they just afraid of it, or they don't understand?

George: Our premise for this grant was that patients don't understand their level of asthma control. They feel that they're in control, or they are happy with their poor level of control as long as they don't have to take more medication. So, we're going to try this thrust first before we go into the risks because we think this might be enough to motivate patients. If it doesn't, we'll move forward and look at one other potent barrier to adherence: erroneous health beliefs.

Pleasants: I thought it was a fantastic presentation. It's something that I said yesterday, and you cannot solve a problem unless you can identify a problem. I think clearly the smart inhalers will allow us to identify problems that exist, assuming that they're not using their nebulizer instead of a smart inhaler. We need a smart nebulizer, by the way.

\section{George: And smart CPAP.}

Pleasants: That, too. There are different models, I think of a 30-d hospitalization and they walk out the door with a smart inhaler where you can monitor the albuterol use and the maintenance use. For a CPAP model, where we start you on this drug and if you show you're adherent we'll waive your copay . . . I think you have to be very creative in all this stuff. And I think it will help some people become adherent, but for some people it won't. But again, you can never solve a problem until you identify it.

George: Right. In the Krishnan study, ${ }^{1}$ they went home with electronic monitors, so these were people who had just been released after a lifethreatening event for asthma, and to think that ICS adherence had dropped to $50 \%$ or lower within a week of discharge! ${ }^{2}$ You'd think if there was a teachable moment where people might have an epiphany and see the writing on the wall, and to think this group of adults still went home and didn't take their medicines is really interesting. I think you're right, it's going to work for everyone but not everyone will accept it.

Giordano: Were any of the researchers able to establish a correlation between the rate of non-adherence and the number of comorbidities?

George: There is clearly a correlation between the number of drugs taken per day or the number doses per day. That's kind of a proxy for comorbidity.

Giordano: Maureen, in your opinion, if we want to identify in advance potential non-adherers for more intense education, in other words, create a list of usual suspects?

George: Put everyone on it.

Giordano: What characteristics should we look for?

George: Expect all your teenagers, and individuals who are disenfranchised from medical care, whether they've experienced institutional racism, maybe they endorse an alternative model of health care that is not from medical professionals, maybe they are immigrants. You might expect that they would all question whether the diagnosis is right, if the treatment is needed, and if the treatment is safe.

Mann: I was wondering if you could give the top 3 things for non-adherence that you should discuss with your patients. And I want to ask if one of the top reasons - in my mind, for a lot of the COPD and asthma patients that I used to take care of or currently take care of are in my family-is that they're worried that they're going to get hooked on the drugs. They all say this to me: "If I start this oxygen or this albuterol, I'm going to need it forever." They think they're going to be hooked on it or dependent on it, so to me that's in the top 3. 
George: I think we need a whole conference just on this because it's beliefs and attitudes. A lot of the work I do in medical anthropology is documenting all these beliefs and attitudes, and we know a lot more about these in asthma than in COPD. But in asthma we know that they think they're being over-medicated, they believe they become addicted or tolerant if they take it every day, and they believe that physicians and nurses get kickbacks from industry to prescribe these medicines just to make money. In COPD I think you have a different set of beliefs, such as addiction to oxygen and some other things, but we know much less about COPD than we know asthma.

Mann: I think for clinicians to know these are the top reasons we really need to explore with these patients would be great.

George: I think a full meeting on this would be really helpful, but I may be biased.

\section{REFERENCES}

1. Krishnan JA, Riekert KA, McCoy JV, Stewart DY, Schmidt S, Chanmugam A, et al. Corticosteroid use after hospital discharge among high-risk adults with asthma. Am J Respir Crit Care Med 2004;170(12): 1281-1285.

2. Arcia A, Merrill JA, Bakken S. Consumer engagement and empowerment through visualization of consumer-generated health data. In: Edmunds M, Hass C, Holve E, eds. Consumer informatics and digital health: Solutions for health and health care. New York, NY: Springer Publishing; in press. 